\title{
Article
}

\section{Theatres without borders: a systematic review of the use of intraoperative telemedicine in low- and middle-income countries (LMICs)}

Subbiah Ponniah, Hariharan, Shah, Viraj, Arjomandi Rad, Arian, Vardanyan, Robert, Miller, George and Malawana, Johann

Available at https://clok.uclan.ac.uk/39449/

Subbiah Ponniah, Hariharan, Shah, Viraj, Arjomandi Rad, Arian, Vardanyan, Robert, Miller, George and Malawana, Johann (2021) Theatres without borders: a systematic review of the use of intraoperative telemedicine in lowand middle-income countries (LMICS). BMJ Innovations. ISSN 2055-642X

It is advisable to refer to the publisher's version if you intend to cite from the work. http://dx.doi.org/10.1136/bmjinnov-2021-000837

For more information about UCLan's research in this area go to http://www.uclan.ac.uk/researchgroups/ and search for <name of research Group>.

For information about Research generally at UCLan please go to http://www.uclan.ac.uk/research/

All outputs in CLoK are protected by Intellectual Property Rights law, including Copyright law. Copyright, IPR and Moral Rights for the works on this site are retained by the individual authors and/or other copyright owners. Terms and conditions for use of this material are defined in the policies page. 
5 AUTHORS:

6 Hariharan Subbiah Ponniah ${ }^{1 *}$; Viraj Shah ${ }^{1 *}$; Arian Arjomandi Rad ${ }^{1,2}$; Robert Vardanyan ${ }^{1,2}$;

7 George Miller 2,3 ; Johann Malawana ${ }^{2,3}$.

Theatres without Borders: A Systematic Review of the Use of Intra-Operative Telemedicine in Low- and Middle-Income Countries (LMICs)

(Running Head: Telesurgery in LMICs)

\section{INSTITUTION:}

1. Department of Medicine, Faculty of Medicine, Imperial College London, London, United Kingdom.

2. The Healthcare Leadership Academy, London, United Kingdom.

3. University of Central Lancashire Medical School, Preston, United Kingdom.

*authors contributed equally

Corresponding author: Arian Arjomandi Rad, Imperial College London, Department of Medicine, Faculty of Medicine, South Kensington Campus, Sir Alexander Fleming Building, London, United Kingdom. Email: arian.arjomandi-rad16@imperial.ac.uk

Word count: 3840

Number of Figures: 1

Number of Tables: 1

Conflict of interest: none

Funding: none

Data availability: data collection form and search results are available on enquiry to the 24 corresponding author (A.AR) 


\section{$26 \underline{\text { Abstract }}$}

27 Objective: This systematic review aims to provide a summary of the use of real time 28 telementoring, tele-surgical consultation and telesurgery in surgical procedures in patients in 29 LMICs.

30 Design: A systematic review was conducted in accordance with the Preferred Reporting Items 31 for Systematic Reviews and Meta-Analyses (PRISMA) statement and the Cochrane 32 Collaboration published guidelines.

33 Data sources: EMBASE, MEDLINE, Cochrane, PubMed and Google Scholar were searched 34 for original articles and case reports that discussed telementoring, telesurgery or tele-surgical consultation in countries defined as low or middle income (as per the World Banks's 2021 2022 classifications) from inception to August 2021

37 Eligibility criteria for selecting studies: All original articles and case reports were included if 38 they reported the use of telemedicine, telesurgery or tele-surgical consultation in procedures conducted on patients in LMICs.

40 Results: There were 12 studies which discussed the use of telementoring in 55 patients in 41 LMICs and included a variety of surgical specialities. There was 1 study that discussed in use 42 of telesurgical consultation in 15 patients in LMICs and 1 study that discussed the use of 43 telesurgery in 1 patient.

44 Conclusion: The presence of intraoperative telemedicine in LMICs represents a principal move towards improving access to specialist surgical care for patients in resource-poor settings. Not only do several studies demonstrate that it facilitates training and educational opportunities,

47 but it remains a relatively frugal and efficient method of doing so, through empowering local 48 surgeons in LMICs towards offering optimal care whilst remaining in their respective communities. 


\section{$51 \quad$ Key points}

52 - The development of global telecommunications, digital health technologies, and 53 intraoperative navigation, guidance, and streaming have exponentially increased the 54 accessibility to telesurgery and wider telemedicine in LMICs.

55 - Intraoperative telemedicine promises to improve access to specialist surgical care for patients

56 in resource-poor settings through intraoperative guidance and telesurgical consultations.

57 - Intraoperative telemedicine and telementoring can alleviate the surgical brain-drain of many

58 LMIC's through cost-effective and efficient training and educational opportunities.

59 - The fields in which this technology has been applied are general surgery, plastic surgery, 60 urology, otolaryngology, and neurosurgery.

61 - A lack of an organised, unified system in providing telementoring, telesurgery, and

62 telesurgical consultations to LMICs still exists and, therefore, many hurdles remain in its 63 uptake, provision, and development in LMICs.

64

65

66

67

68

69

70

71

72

73 
Introduction

77 It is well-documented that there is a growing disparity ${ }^{1,2}$ in the quality of healthcare delivered around the world, particularly evident in Low- and Middle-Income Countries (LMICs) in the

field of surgery. Concomitantly, the lack of both infrastructure and local training opportunities in these settings has led to many competent healthcare professionals leaving their countries in search of specialist training and professional development opportunities ${ }^{3-5}$. This underpins the "brain drain" phenomenon seen commonly in LMICs, a process that is often exacerbated by the lack of rigorous domestic training structures ${ }^{1,6}$. With increasing rates of morbidity, there is an ever-increasing demand for specialist surgeons globally and, as a result, for surgical training posts especially in $\mathrm{LMICs}^{7}$. A flourishing global telecommunications industry has led to an increase in the ease of exchange of information, especially medical information, culminating in the emergence of telemedicine - the use of technology to deliver care ${ }^{8}$. This growing sector has already commenced its role in bridging the gap in the delivery of care between LMICs and High-Income Countries (HICs) ${ }^{9,10}$.

Telemedicine has been applied to various aspects of surgical care ${ }^{11}$, but telemedicine during surgical procedures can be broadly categorised as telesurgery, telementoring and tele-surgical consultation $^{12,13}$. Telementoring can be defined as the use of telecommunication to guide and assist the operating surgeon remotely during a procedure - ranging from basic audio commands to the use of annotation on screen to guide the surgeon ${ }^{13,14}$. Tele-surgical consultation is similar to telementoring except the difference is both surgeons are experienced and use telecommunication platforms to work through a complicated case ${ }^{15}$. Telesurgery can be defined as the use of telecommunication in conjunction with a surgical robot to remotely operate on a patient $^{13,14}$. 
101 Although studies in the past have investigated the prevalence and implementation of the 102 various modes of intraoperative telemedicine or the use of a particular division of 103 intraoperative telemedicine in a particular surgical specialty ${ }^{16-19}$, there are no reviews that have examined the use of intraoperative telemedicine in LMICs, especially the implementation of it in intra-operative care. This systematic review aims to provide a summary of the use of real time telementoring, tele-surgical consultation and telesurgery in surgical procedures in patients in LMICs.

Methods

\section{Literature Search Strategy}

111 A systematic review was conducted in accordance with the Preferred Reporting Items for Systematic Reviews and Meta-Analyses (PRISMA) statement and the Cochrane Collaboration published guidelines. EMBASE, MEDLINE, Cochrane, PubMed and Google Scholar were searched for original articles and case reports that discussed telementoring, telesurgery or telesurgical consultation in countries defined as low or middle income (as per the World Banks's 2021-2022 classifications $)^{20}$ from inception to August 2021. A priori protocol was devised for the following study, available upon request. The search terms used included "Telementoring", “Telesurgery", "Tele-surgical consultation", "Low Income" and "Middle Income" - the entire search criteria, which was used across all databased, is attached in appendix 1. Further articles were identified through a manual search of the references lists of articles found through the original search and use of the 'related articles' function on MEDLINE. The only limits used were the mentioned time frame and English language. 
125 All original articles and case reports were included if they reported the use of telemedicine,

126 telesurgery or tele-surgical consultation in procedures conducted on patients in LMICs. Studies

127 were excluded from the review if: 1) inconsistencies in the data impeded extraction of data, 2)

128 the study was performed in an animal model, 3) there was no mention of any surgical

129 procedures performed on patients and 4) the surgeries performed were in countries deemed to

130 be high in income. Reviews, editorials, abstracts from meetings and preclinical studies were

131 excluded. By following the aforementioned criteria, two reviewers (H.SP. and V.S.)

132 independently selected articles for further assessment following title and abstract review. A

133 third independent reviewer (A.AR.) resolved any disagreements between the two reviewers.

134 Potentially eligible studies were then retrieved for full text assessment. The software used for 135 the here described process was Covidence (Melbourne, Australia).

\section{Data extraction and critical appraisal of evidence}

138 All full texts of retrieved articles were read and reviewed by two authors (H.SP. and V.S.) and a unanimous decision was made regarding inclusion or exclusion of studies. When there was

140 disagreement, the final decision was made by a third reviewer (A.AR.) Using a pre-established

141 protocol, the following data was extracted: first author, study design, type of surgical specialty 142 and the surgical procedure(s) discussed, population number, type of intraoperative

143 telemedicine used, method in which the type of intraoperative telemedicine was implemented,

144 and the qualitative and quantitative main outcomes. A data extraction sheet for this review was 145 developed and pilot-tested using 3 randomly selected included studies and subsequently was 146 refined accordingly. Data extraction was performed by 2 review authors (H.SP. and V.S.) who 147 carried out the process in duplicate on two separate extraction sheets. Correctness of the 148 tabulated data was validated by a third author (A.A.R) who evaluated both extraction sheets 149 and assed full texts where incongruences existed. 
150 Due to the high heterogeneity of the studies quality scoring through the use of the available 151 assessment tolls was decided not be carried our by the research group.

152

$153 \underline{\text { Results }}$

\section{Study selection}

155 The literature search identified 1574 articles, of which 991 were screened following 156 deduplication and 143 were full-text reviewed and assessed in accordance with the inclusion

157 and exclusion criteria. Following critical appraisal, a total of 12 studies $^{21-32}$ were included in 158 this review, featuring 71 patients. Figure 1 illustrates the entire study selection process. A 159 summary of the studies collected and their respective designs, type of intraoperative 160 telemedicine used and its implementation as well as the main reported outcomes are found in 161 Table 1.

162

163 Telementoring

164 There were 12 studies which discussed the use of telementoring in 55 patients in LMICs and 165 included a variety of surgical specialities ${ }^{21-27,29-32}$.

166

167 Telesurgical consultation

168 There was 1 study that discussed in use of telesurgical consultation in 15 patients in LMICs ${ }^{28}$.

170 Telesurgery

171 There was 1 study that discussed the use of telesurgery in 1 patients in LMICs $^{26}$. 
176 This systematic review is the first of its nature to provide a summary of the intraoperative uses

177 of telemedicine within surgery in LMICs. The results are indicative of the successes of specific

178 modes of telemedical approaches in such landscapes, most prominently telementoring ${ }^{21-27,29-}$

$179{ }^{32}$, these examples represent both recent and limited phenomena. Care must be given in 180 recognising disparities in the standard of surgical care in even highly-specialist settings across

181 LMICs ${ }^{33,34}$, with some of the most recent literature describing only novel approaches.

183 There is evident value to the continued use of intraoperative telemedicine as a novel approach

184 in providing specialist surgical care in resource-limited settings in LMICs; this can be further stratified into positive outcomes in terms of viability ${ }^{30,35}$ and $\operatorname{cost}^{36}$. Whilst there has been cited successful adoption of such approaches in LMICs since $2000^{24,37}$, more contemporary technological advancements including the use of wearable technology ${ }^{27,29}$ and augmented reality ${ }^{30}$ may further encourage the growth and uptake of intraoperative telemedicine in years to follow as well as drive further improvements to overcome current technological shortcomings. All procedures undertaken within the 12 papers included in this review were performed to successful completion via intraoperative telemedicine suggesting the need for further investment in supporting the refinement and development of such technologies accordingly. This will allow for greater mainstream adoption of telementoring and telesurgery within LMIC settings in conjunction with ameliorating the cost-effectiveness of required technologies.

\section{Surgical education versus urgent care provision}

198 This review raises questions pertaining to whether the primary objectives of intraoperative 199 telemedicine in LMICs should pivot towards bridging gaps in the lack of patient accessibility 
to specialist surgical opinion and care in remote regions, or rather, be used primarily as

201 economical instruments of training and surgical education. Whilst the operative procedures

202 described in the 12 articles in this review all assumed a middle line between the provision of

203 specialist care and provision of training/mentoring, this line was nuanced in particular cases notably the description of reconstructive techniques in the McCullough et al. study (2018) and a phacoemulsification surgery in the Geary et al. study $(2019)^{31,32}$. In the latter example, the designated telementor would preoperatively review the case information prior to determining cases suitable for telementored guidance. Subsequently, the delivery of the telementoring sessions followed a structured approach through the establishment of learning objectives. This stood out in marked contrast to the case report by Pradeep et al. (2006) ${ }^{27}$ describing a patient with debilitating hyperparathyroidism due to a persistent parathyroid tumour that had failed to be removed previously. It was noted in this report that the patient's condition was such that travel to a specialist centre would have been unfeasible, thus making an urgent telementoring approach particularly relevant to deliver satisfactory care. The difference in these highlighted approaches suggests the multifaceted applications of intraoperative telemedicine to delivering surgery in LMICs - this provides weight to its use in both elective surgeries (where a greater focus may be placed on training) and in delivering emergency care in urgent situations (where training, albeit provided, is less prioritised). It also highlights the impact of pre-operative coordination to maximise the effectiveness of intraoperative telemedicine for training purposes, as evidenced by the results of the post-CPD-session questionnaire in the Geary et al. study (2019) where $100 \%$ of surgeons agreed or strongly agreed that this approach increased their confidence and surgical skill ${ }^{32}$. 
In addition, this review highlights the applicability of intraoperative telemedicine across a

225

226

227

228

229

230

231

232

233

234

235

236

237

238

239

240

241

242

243

244

245

246

247

diverse and wide-ranging domain of surgical subspecialties comprising 5 of the list of 10 recognised surgical specialties as defined by the Royal College of Surgeons of England including general surgery, plastic surgery, urology, otolaryngology, neurosurgery ${ }^{38}$ as well as ophthalmology. Hence, there is opportunity to trial the use of intraoperative telemedicine for complex cases within subspecialties not covered by this list. Earlier applications of intraoperative telemedicine in surgery in LMICs were centred around laparoscopic and endoscopic procedures, utilising a telementored approach ${ }^{21,22}$. The basis of this surrounded the fact that cameras are incorporated natively into these procedures such that the surgical field of view is identical for both the operating surgeon and the remote surgical 'mentor' ${ }^{31}$. The introduction of teleproctering via the use of wearable technology including Google Glass (Google Inc., Mountain View, California) ${ }^{39}$ has led to the potential for implementing intraoperative telemedicine in surgeries traditionally classed as 'open surgeries', seen most prominently in the McCullough et al. study $(2018)^{31}$. This study exemplified its use for supporting local surgeons in Mozambique with reconstructive procedures comprising regional flaps, z-plasties and skin grafts for the care of patients with burn contractures ${ }^{31}$. Again, this is suggestive of the fact that the delivery of intraoperative telemedicine in LMICs is continually evolving parallel to the evolution of technology. As the incidence of non-communicable diseases grows at disproportionate rate in LMICs as a direct consequence of the epidemiological transition and growing industrialisation ${ }^{40,41}$, the incidence of unmet need including that of cardiovascular disease ${ }^{42}$ and road traffic injuries ${ }^{43}$ in LMICs is also increasing; with the latter accounting for $90 \%$ of the global burden of such injuries despite a significantly lower prevalence of predisposing risk factors within these settings ${ }^{44}$. Therefore, it is not only essential for global efforts to focus on improving access to specialist cardiothoracic and trauma care in the long-term but also necessary to provide innovative solutions to the 
ongoing lack of trained surgical personnel in the short-term. This is an avenue where viable implementation of intraoperative telemedicine could play a specialised role in improving $\operatorname{access}^{33,45}$.

\section{Heterogeneous platforms of intraoperative telemedicine in LMICs}

The heterogeneity in the examples of intraoperative telemedicine in LMICs, that met the inclusion criteria for this review, made it difficult to ascertain the extent of the role played by the specific method of intraoperative telemedicine employed on the overall outcomes for each included study. Of the 12 studies included in this review: 7 were aggregated together as adopting a standard "camera \& live video-streaming" technique, a further 2 adopted similar approaches but allowed for additional telerobotic control of the camera to optimise angles and viewpoints by the 'surgical mentor' $25,26,2$ used 'wearable technology + live video-streaming' techniques ${ }^{29,31}$ with both of these studies consistently deploying Google Glass (Google Inc., Mountain View, California) $)^{39}$ to do so and a further singular study used the Proximie augmented reality platform ${ }^{30,46}$. In addition to the aforementioned potential of integrating wearable technology into open surgery, wearable technology allows for greater practical functionality of intraoperative telemedicine systems. Google Glass can be operated verbally, allowing an operating surgeon the ability to use both hands unencumbered whilst ensuring a sterile operating environment is maintained ${ }^{31}$. The use of telerobotic control in enhancing the efficiency of intraoperative telepresence systems in LMICs has also been made apparent via the Netto et al. (2003) study ${ }^{26}$. In this report, the remote surgeon was able to control the imaging presented via control of a robot attached to a laparoscope, achieved through the manipulation

271 of controllers embedded into the remote computer (AESOP300, ComputerMotion Inc., 272 California) $)^{47}$. The success of robotic control may provide tangible benefits such as maximising 273 efficiency by reducing operating times, which may off-set some of the time delays posed by 
intraoperative telepresence including poor connection and $\operatorname{lag}^{48,49}$. Although coalescing

275 platforms such as Proximie into intraoperative telemedicine brings forwards the innate set of 276 advantages of augmented reality, its most relevant applications might lie in the versatility of

277 such platforms such that they are cross-compatible with a range of devices. This enables a more

278 realistic introduction of intraoperative telemedicine in LMICs as the technology can be utilised

279 more accessibly through portable tablets. Platforms such as these provide more optimal

280 methods of delivering information to the operating surgeon, through the sharing of gestures to

281 guide the surgeon on practical techniques relevant to the procedure at hand. ${ }^{30}$ Nevertheless, all

28212 studies included in the review describe telepresence that allows simultaneous audio and

283 visual communication between the operating and remote surgeons and it is this feature that is most central to the success of intraoperative telemedicine.

\section{Future directions}

287 The majority of examples of intraoperative telemedicine described in this review are trials.

288 Although the concept of telemedicine, specifically telementoring, is not entirely novel, its use intraoperatively in LMICs remains one that requires significant further analysis from a public health perspective $\mathrm{e}^{48}$. There is wide variability in the proposed costs associated with different methods of intraoperative telepresence. Although the Geary et al. study (2019) suggests that there is a $\$ 8,000$ to $\$ 20,000$ USD fee for the audiovisual technology required using a 'streaming' approach ${ }^{32}$, alternative technologies including wearables have drastically different price points. Google Glass is estimated to cost $\$ 999 \mathrm{USD}^{50}$ and, at time of the review, is only available to specific partners (only 2 out of 32 of which serve geographical regions that comprise $\mathrm{LMICs})^{51}$. Whilst alternative wearables are available ${ }^{52}$, these have not been trialled as robustly in intraoperative clinical settings in LMICs. Literature relating to the costeffectiveness of using either robotic arms or augmented reality in surgery is also notably sparse. 
Conversely, it must be stated that the most significant costs associated with using intraoperative

300

301

302

303

304

305

306

307

308

309

310

311

312

313

314

315

316

317

318

319

320

321

322

telemedicine in LMICs are fixed, only excluding the costs of subscriptions to video streaming software ${ }^{32}$. Hence, there is sufficient rationale for conducting a large-scale costs analysis of the use of different forms of intraoperative telemedicine in LMICs - this should soundly evaluate the one-off fixed fees associated with their use against alternative options such as a physical presence of experienced overseas surgeons acting as regular visitors. Only 3 of the 12 papers included in this review ${ }^{23,28,32}$ provided satisfactory information relating to the costs associated with technology employed, with only the Davis et al. (2016) study providing a sufficiently indepth total cost analysis.

Another avenue for incorporating intraoperative telemedicine might be through its application in providing continuous professional development (CPD). 5 of the 12 papers that met the inclusion criteria for the review ${ }^{22,26,29,31,32}$ described telementoring opportunities that spanned multiple sessions. This was most exemplified in the Forgione et al. Study (2015) where, upon completion of a 4-week telementored fellowship between teams in Italy and Russia, the operating surgeon gained proficiency to operate whilst being telementored and further went on to undertake 25 colorectal procedures without any remote supervision, despite no initial experience with the procedure. Transparently, there are clear grounds to expand the use of intraoperative telemedicine in LMICs as a more efficient model for supplementary continuous training and one that allows surgeons to be trained from their respective geographical regions without travelling. Over a longer time period, this would negate the effects of the "brain drain"5 that encourages talented surgeons from LMICs to travel overseas to receive more specialist training and subsequently remain there permanently. This can additionally be further expanded to wider aspects of surgical and, potentially, anatomical education, including improving access 
to undergraduate medical teaching in resource-poor settings, although the efficacy of this

324 remains to be studied.

\section{Weaknesses of telesurgery}

327 This review has recognised that there are many integral limitations of intraoperative telemedicine that exist across the papers selected. Quality control remains an important issue, in part due to the diversity in the availability of methods of delivering it. The consistency of operations is heavily skewed by the limitations of particular hardware and software used. As all the papers describe elements of streaming, the technological faults of cameras, computers and/or portable devices and software that provide both streaming and receipt of audiovisual signals can heavily hinder the efficacy of any one particular procedure. As there is no single or widely-accepted system optimised to the delivery of care in this way, the utility of intraoperative telemedicine in LMICs is unpredictable. This is reinforced by the fact that the use of existing infrastructure in LMICs would be preferred, and technology available in greater abundance in LMICs may not necessarily match that described in this review's highlyspecialised settings in terms of factors spanning speed, reliability and display quality ${ }^{53}$. Financial barriers such as this one still make the use of intraoperative telemedicine in LMICs, even telementoring, a complex one. Although a relatively frugal innovation if robust systems

341 comprising high-quality computing, recording and streaming equipment are available, it is 342 impossible to use a "one-size-fits-all" policy when exploring its applicability to LMICs as a whole and it is likely heavily dependent on the specific region in question. This is particularly poignant due to the fact it is the least-resourced settings that could benefit the most from such an innovation. 
347 Access to reliable local wireless networks was seen as fundamental to ensure a sufficient 348 quality of transmission of audiovisual signal ${ }^{29}$ and the overwhelming majority of issues across 349 this review that arose with intraoperative telemedicine were rooted in shortcomings in this area. 350 Although in many cases including the Nadjafi-Semnani et al. paper (2008) study ${ }^{21}$, sufficient image quality and connection stability was maintained, there are many cited examples of where this has not held true. The Rosser et al. study (1999) ${ }^{24}$ notably describes the fact that disconnection was experienced in 4 of the 5 included patients due to a combination of electrical issues. Furthermore, time delays represent an area of challenge for intraoperative telemedicine in all scenarios, including LMICs. Time delays are more pronounced where there is further distance between the remote and operating teams ${ }^{25}$ and although no paper included in this review established this as a cause of significant detriment, it is worth exploring as an area of study to further improve the efficiency of intraoperative telemedicine. On a similar nature, although time difference between the remote and operating teams was not cited as a major inconvenience in any of the papers included in this review, it is a point for furtherconsideration in aspiration of increasing intraoperative telemedicine's role in non-elective surgeries.

Finally, ethico-legal considerations including the protection of patient privacy and anonymity must be further evaluated prior to the expansion of intraoperative telemedicine in LMICs; a potential avenue for how this may be achieved is through the use of private communication networks as outlined in the Forgione et al. study $(2015)^{22}$ but this warrants further investigation.

\section{Limitations of review}

This systematic review is also subject to some inherent limitations. Primarily, due to the nature of the studies included in the review, many were unable to adopt a methodology consisting of blinding and, although this was unavoidable in most cases, it still represents a source of 
significant cognitive bias. This review was additionally limited by the low sample sizes of all studies included within it, with all studies having < 16 patients and thus exhibiting bias through statistical skew.

376 The majority of studies that met the inclusion criteria for this review were single-arm interventional studies that are known to contain bias and are sources of error. The incorporation of randomised controlled trials into this review may have improved its validity, but this was restricted by the availability of data.

Another source of bias linked to reviews of this nature is publication bias, referring to the common phenomenon seen that published academic literature is far more likely to report statistically significant findings in comparison to insignificant findings ${ }^{54}$. Thus, this review is prone to publication bias which is made more significant by the inclusion of case reports. As a result of the consequences of this bias in conjunction with the low samples described in this review, meta-analysis has not been conducted.

This review contains literature published over a 22-year time period between 1999 and 2019 inclusive. As a result, there has been significant technological advancements since the publication dates of earlier studies included in this review and, where this is applicable, these studies' conclusions were recognised in the context of the time of their publication. Where conclusions had been outdated by novel published literature, this was understood and these conclusions were not used to guide the scope of this review. In addition, many of the included studies suffer from a lack of longitudinal aspect to them to allow for follow-up of either patient outcomes post-operatively or the retention of surgical skills by the operating surgeon. This renders it difficult to examine the long-term benefits of intraoperative telemedical approaches 
in LMICs. Hence, there is adequate grounding for the planning of additional prospective randomised studies to measure both these characteristics and observe the impact of this innovation in clinical practice.

400

401 Conclusion

402

The presence of intraoperative telemedicine in LMICs represents a principal move towards improving access to specialist surgical care for patients in resource-poor settings. Not only do several studies demonstrate that it facilitates training and educational opportunities, but it remains a relatively frugal and efficient method of doing so, through empowering local surgeons in LMICs towards offering optimal care whilst remaining in their respective communities. The presence of tele-surgery continues to be negligible in LMICs due to limitations including the inaccessibility of technology, lack of infrastructure or funding difficulties. However, whilst the implementation of telesurgery has been scarce, many studies have demonstrated that the use of other forms of telemedicine within surgery are gaining significant momentum; these comprise telementoring featuring wearable technology, augmented reality or audio-visual streaming alongside either unidirectional or bidirectional communication. The advent of COVID-19 has certainly streamlined the implementation of intraoperative telemedicine in $\mathrm{HICs}^{55}$, which provides an opportunity to learn more about how 415 best it can be suited to improving care in LMICs. This is complemented by the 17 Sustainable 416 Development Goals (SDGs) as set out by the United Nations to be achieved by 2030, which 417 include provision of reliable and sustainable energy and the fostering of innovation ${ }^{56}$. Although current use is confined to limited settings, it is possible that the trajectory of applications of intraoperative telemedicine will follow that of concurrent technological development in LMICs. Nevertheless, prospective randomized studies will be need ed to assess the "real-world" impact of this technology. 
423 Concept and design, data interpretation, drafting article, approval of article: HSP, VS, AAR,

424 RV, GM, JM. Data collection, drafting article: HSP, VS, AAR, RV. Supervision, Critical 425 revision: AAR, RV, GM, JM 
Table 1: Studies included discussing the use of intraoperative telemedicine in LMICs.

\begin{tabular}{|c|c|c|c|c|c|c|c|c|}
\hline Study & Year & $\begin{array}{l}\text { Study } \\
\text { Design }\end{array}$ & Country & $\begin{array}{c}\text { Type of } \\
\text { Surgery/Surgical } \\
\text { Specialty }\end{array}$ & $\begin{array}{l}\text { Populatio } \\
\text { n Number } \\
+\end{array}$ & $\begin{array}{l}\text { Type(s) of } \\
\text { intraoperative } \\
\text { telemedicine } \\
\text { discussed } \\
\end{array}$ & $\begin{array}{l}\text { Method of intraoperative } \\
\text { telemedicine implementation }\end{array}$ & Main reported outcomes \\
\hline $\begin{array}{l}\text { Geary et } \\
\text { al. }\end{array}$ & 2019 & $\begin{array}{l}\text { Prospective } \\
\text { study }\end{array}$ & $\begin{array}{c}\text { USA* } \\
\text { and Peru }\end{array}$ & $\begin{array}{c}\text { Ophthalmology - } \\
\text { Phacoemulsificatio } \\
n\end{array}$ & 12 & - Telementoring & $\begin{array}{l}\text { Cases were sent to mentor } \\
\text { surgeon by field surgeon and } \\
\text { were screened based on } \\
\text { whether procedure was } \\
\text { compatible for remote } \\
\text { guidance and then a pre- } \\
\text { operative discussion took } \\
\text { place to structure the teaching } \\
\text { and learning objectives for } \\
\text { that session. } \\
\text { Live phacoemulsification was } \\
\text { streamed over internet using } \\
\text { audio-visual equipment, } \\
\text { accompanied with Zoom, a } \\
\text { video conferencing software, } \\
\text { which enabled the mentor } \\
\text { Surgeon to be in constant } \\
\text { touch with the operating } \\
\text { surgeon. } \\
\text { - A survey distributed } \\
\text { following the mentorship to } \\
\text { assess its acceptability as well } \\
\text { as a self-assessment of their } \\
\text { development in their surgical } \\
\text { skills. }\end{array}$ & $\begin{array}{l}\text { - Latency recorded during } \\
\text { surgery was well within margin } \\
\text { of acceptability and video } \\
\text { quality was clear enough for } \\
\text { mentoring surgeon to observe } \\
\text { the anatomy and manipulation } \\
\text { of instruments. } \\
\text { - } 7 \text { Surgeons over } 4 \text { sessions } \\
\text { performed } 12 \\
\text { phacoemulsification surgeries. } \\
11 \text { of the } 12 \text { patients achieved } \\
\text { the best visual acuity } \\
\text { postoperatively. } \\
\text { - } 4 \text { Surgeons completed the post } \\
\text { mentorship survey and } 100 \% \\
\text { agreed or strongly agreed that } \\
\text { learning objectives had been } \\
\text { met and the teaching had } \\
\text { enhanced their confidence and } \\
\text { skills in the procedure. }\end{array}$ \\
\hline
\end{tabular}




\begin{tabular}{|c|c|c|c|c|c|c|c|c|}
\hline $\begin{array}{l}\text { McCullou } \\
\text { gh et al. }\end{array}$ & 2018 & $\begin{array}{l}\text { Prospective } \\
\text { study }\end{array}$ & $\begin{array}{l}\text { USA* } \\
\text { and } \\
\text { Mozamb } \\
\text { ique }\end{array}$ & $\begin{array}{c}\text { Plastics- } \\
\text { Reconstructive } \\
\text { Surgery }\end{array}$ & 12 & - Telementoring & $\begin{array}{l}\text { - Cases were sent to mentor } \\
\text { surgeon by field surgeon and } \\
\text { were screened based on } \\
\text { operational difficulty and } \\
\text { educational value to surgeon, } \\
\text { including novel techniques for } \\
\text { common presentations seen } \\
\text { and dealt by the field surgeon. } \\
\\
\text { - Google Glass with the ability } \\
\text { to stream in real time was } \\
\text { used to facilitate a } \\
\text { reconstructive surgeon in } \\
\text { USA to guide the surgeon in } \\
\text { Mozambique over a period of } \\
6 \text { months. }\end{array}$ & $\begin{array}{l}\text { - } 12 \text { Surgical Procedures were } \\
\text { remotely guided by the mentor } \\
\text { surgeon. There were no patient } \\
\text { complications. } \\
\text { - Both mentor and field surgeon } \\
\text { reported some disturbances in } \\
\text { video, mainly image distortion } \\
\text { and over-light exposure, } \\
\text { alongside latency in streaming } \\
\text { and connection disruption. }\end{array}$ \\
\hline $\begin{array}{l}\text { Greenfield } \\
\text { et al. }\end{array}$ & 2018 & Case Report & $\begin{array}{l}\text { Lebanon } \\
* \text { and } \\
\text { Palestine }\end{array}$ & $\begin{array}{c}\text { Plastics- } \\
\text { Reconstructive } \\
\text { Surgery }\end{array}$ & 1 & - Telementoring & $\begin{array}{l}\text { - Operating surgeon in Gaza } \\
\text { was guided through a } \\
\text { complex hand reconstruction } \\
\text { of an } 18 \text {-year-old male patient } \\
\text { by the mentor surgeon in } \\
\text { Lebanon. } \\
\text { - Camera rig was set up over } \\
\text { the operating field and using } \\
\text { Proximie, an Augmented } \\
\text { Reality software, the mentor } \\
\text { surgeon was able to highlight } \\
\text { structures on the virtual } \\
\text { surgical field. }\end{array}$ & $\begin{array}{l}\text { - The hand and its range of } \\
\text { movements were assessed over } \\
\text { video and then reconstruction } \\
\text { was performed, resulting in } \\
\text { increase in range of movements } \\
\text { in finger abduction and } \\
\text { extension post-operatively. }\end{array}$ \\
\hline
\end{tabular}




\begin{tabular}{|c|c|c|c|c|c|c|c|c|}
\hline $\begin{array}{l}\text { Davis et } \\
\text { al. }\end{array}$ & 2016 & $\begin{array}{l}\text { Prospective } \\
\text { study }\end{array}$ & $\begin{array}{c}\text { USA* }^{*} \\
\text { and } \\
\text { Vietnam }\end{array}$ & $\begin{array}{l}\text { Neurosurgery - } \\
\text { Neuroendoscopy }\end{array}$ & 15 & - Telementoring & $\begin{array}{l}\text { - An iPad-based tool known as } \\
\text { VIPAR (Virtual interactive } \\
\text { presence and augmented } \\
\text { reality) allowed provision of } \\
\text { long distance, virtual } \\
\text { assistance to local operating } \\
\text { surgeon. } \\
\text { - Local and International trials } \\
\text { conducted initially during } \\
\text { presence of visiting team, had } \\
\text { any immediate assistance } \\
\text { required. }\end{array}$ & $\begin{array}{l}\text { - } 15 \text { neuroendoscopic procedures } \\
\text { were performed in the local } \\
\text { country under the guidance of } \\
\text { mentor surgeons following the } \\
\text { visit, with no significant } \\
\text { complications. }\end{array}$ \\
\hline
\end{tabular}




\begin{tabular}{|c|c|c|c|c|c|c|c|c|}
\hline $\begin{array}{c}\text { Datta et } \\
\text { al. }\end{array}$ & 2015 & $\begin{array}{l}\text { Prospective } \\
\text { study }\end{array}$ & $\begin{array}{c}\text { USA*, } \\
\text { Paragua } \\
\text { y, and } \\
\text { Brazil }\end{array}$ & $\begin{array}{l}\text { General - Inguinal } \\
\text { Hernia Repair }\end{array}$ & 8 & - Telementoring & $\begin{array}{l}\text { Local surgeons in Brazil and } \\
\text { Paraguay were taught the } \\
\text { Lichtenstein inguinal hernia } \\
\text { repair by a visiting } \\
\text { international expert using a } \\
\text { standard protocol. } \\
\text { - Successive procedures } \\
\text { operated by the local surgeon } \\
\text { were streamed in real time } \\
\text { using Google Glass and } \\
\text { enabled guidance by mentor } \\
\text { surgeon in USA. }\end{array}$ & $\begin{array}{l}\text { - } 8 \text { sequential training operations } \\
\text { were conducted, } 4 \text { each in } \\
\text { Brazil and Paraguay. } \\
\text { - Live streaming of the } \\
\text { procedures was successful, and } \\
\text { surgeons were able to } \\
\text { demonstrate proficiency in the } \\
\text { procedure at the completion of } \\
\text { the final case, as judged by the } \\
\text { respective Operative } \\
\text { Performance Rating Scale. }\end{array}$ \\
\hline
\end{tabular}




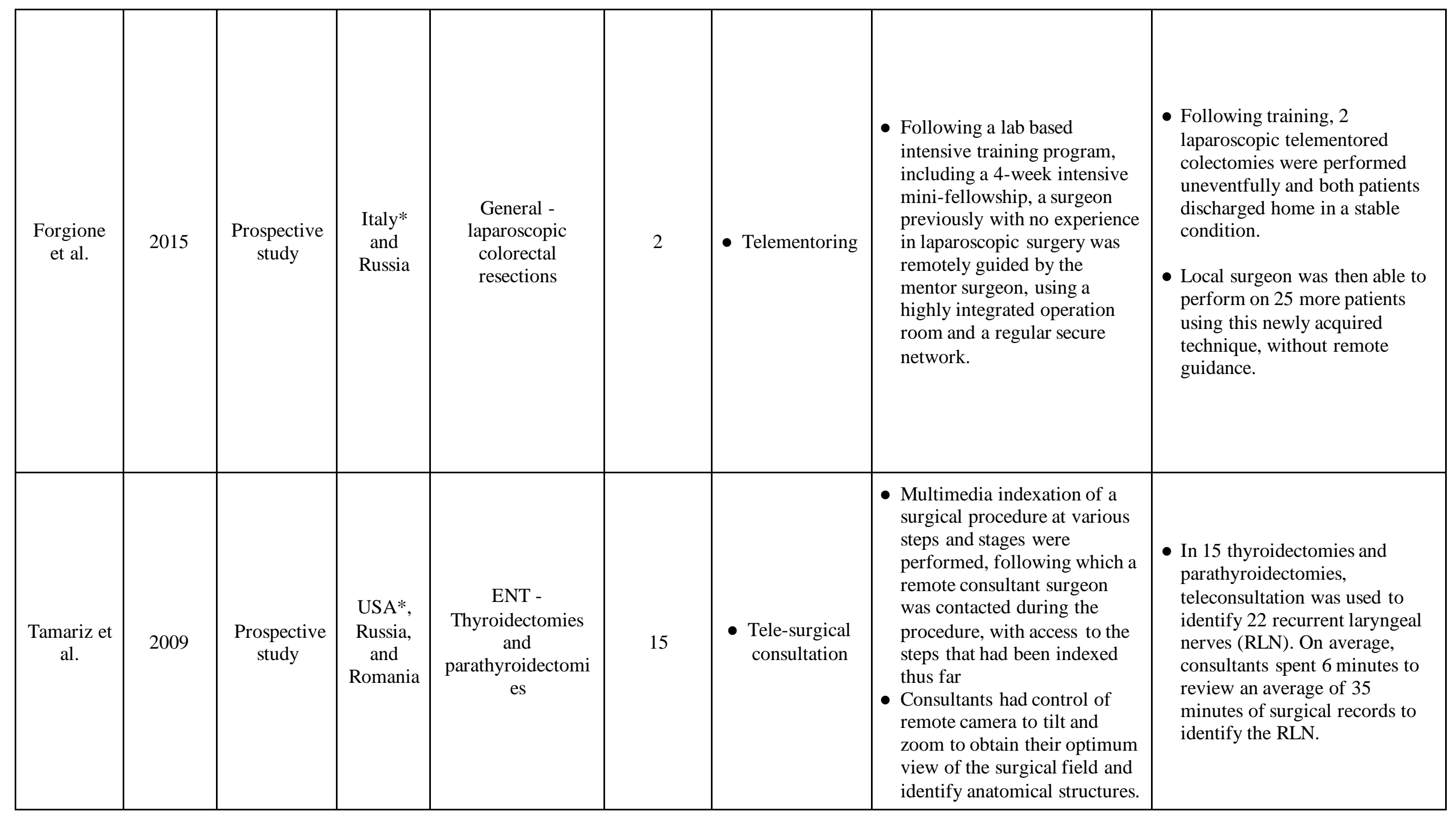




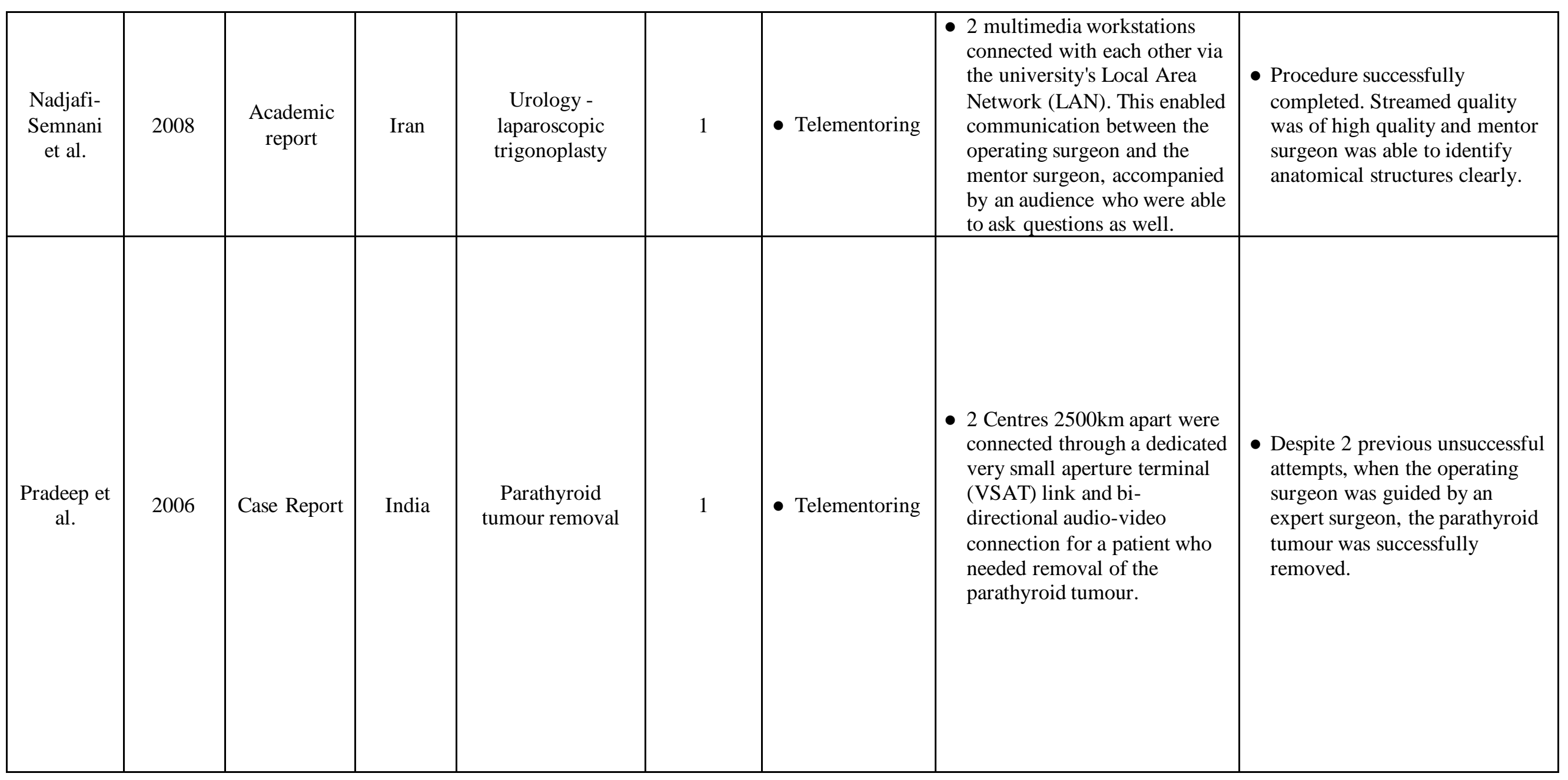




\begin{tabular}{|c|c|c|c|c|c|c|c|c|}
\hline $\begin{array}{l}\text { Netto et } \\
\text { al. }\end{array}$ & 2003 & $\begin{array}{l}\text { Prospective } \\
\text { study }\end{array}$ & $\begin{array}{l}\text { USA* }^{*} \\
\text { and } \\
\text { Brazil }\end{array}$ & $\begin{array}{c}\text { Urology - } \\
\text { laparoscopic } \\
\text { bilateral } \\
\text { varicocelectomy } \\
\text { Percutaneous } \\
\text { nephrolithotomy }\end{array}$ & 2 & $\begin{array}{l}\text { - Telementoring } \\
\text { - Telesurgery }\end{array}$ & $\begin{array}{l}\text { - A laparoscope was fitted to a } \\
\text { surgical robot, AESOP } \\
\text { (Automated Endoscopic } \\
\text { System for Optimal } \\
\text { Positioning), operated } \\
\text { remotely by the mentor } \\
\text { surgeon during the } \\
\text { laparoscopic bilateral } \\
\text { varicocelectomy } \\
\text { - Surgeon was able to control } \\
\text { remotely a PAKY } \\
\text { (Percutaneous Access to the } \\
\text { Kidney) robot to place a } \\
\text { percutaneous needle into the } \\
\text { renal collecting system }\end{array}$ & $\begin{array}{l}\text { - Audio and Video } \\
\text { communication between the } \\
\text { two sites deemed excellent. } \\
\text { - Both procedures completed } \\
\text { without any significant } \\
\text { complications, and both were } \\
\text { asymptomatic at the } 3 \text {-month } \\
\text { follow up. }\end{array}$ \\
\hline
\end{tabular}




\begin{tabular}{|c|c|c|c|c|c|c|c|c|}
\hline $\begin{array}{c}\text { Bauer et } \\
\text { al. }\end{array}$ & 2000 & $\begin{array}{l}\text { Prospective } \\
\text { study }\end{array}$ & $\begin{array}{l}\text { USA* } \\
\text { and } \\
\text { Thailand }\end{array}$ & $\begin{array}{l}\text { Urology- } \\
\text { Laparoscopic } \\
\text { nephrectomy }\end{array}$ & 1 & - Telementoring & $\begin{array}{l}\text { - Connections between } 2 \\
\text { countries established using } \\
\text { ISDN lines, facilitating bi- } \\
\text { directional audio and video. } \\
\text { - Analogue telephone line was } \\
\text { used to enable AESOP } \\
\text { (Automated Endoscopic } \\
\text { System for Optimal } \\
\text { Positioning) enabling the } \\
\text { manipulation of the camera } \\
\text { from a remote location. } \\
\text { - Second analogue POTS line } \\
\text { enabled control of } \\
\text { electrocautery }\end{array}$ & $\begin{array}{l}\text { - Laparoscopic nephrectomy } \\
\text { performed, first recorded time } \\
\text { of control of electrocautery } \\
\text { remotely over a very long } \\
\text { distance }\end{array}$ \\
\hline
\end{tabular}




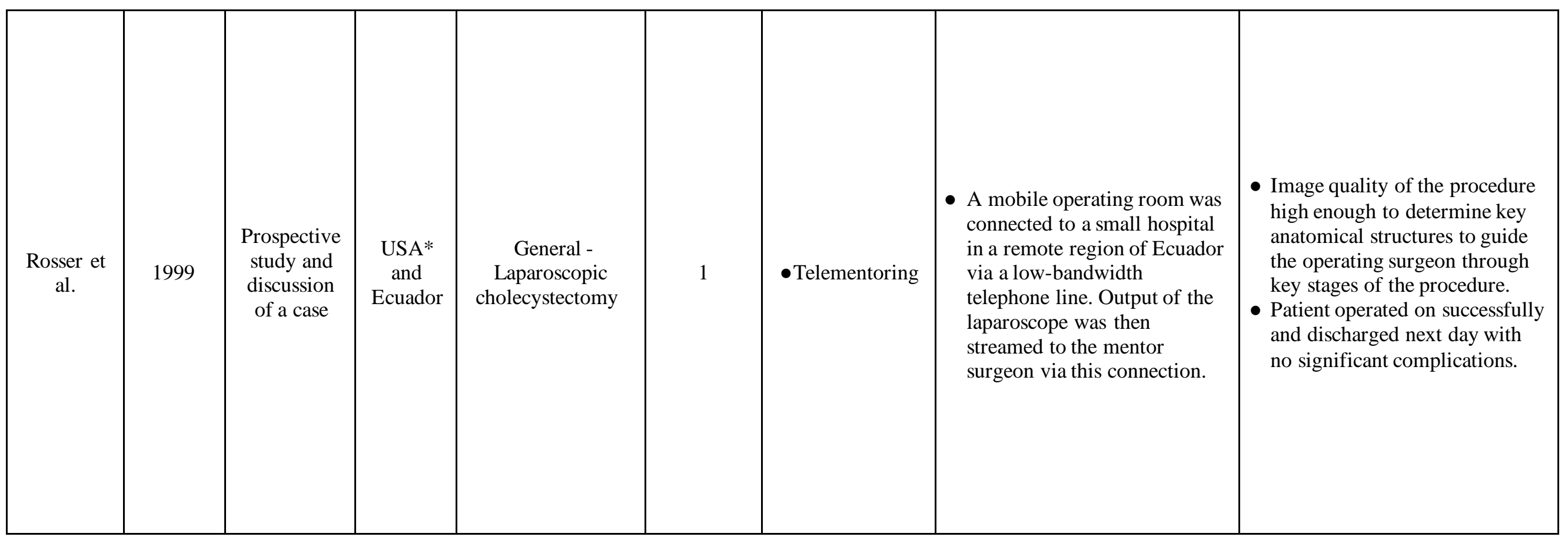

Asterisk $(*)$ denotes the country in which the remote surgeon was based if more than one country was involved in the study.

$\dagger$ Population number included those only in LMICs. 


\section{$\underline{\text { References }}$}

1. Meara JG, Leather AJM, Hagander L, Alkire BC, Alonso N, Ameh EA, et al. Global Surgery 2030: evidence and solutions for achieving health, welfare, and economic development. The Lancet. 2015 Aug;386(9993).

2. Ruger JP, Kim H-J. Global health inequalities: an international comparison. Journal of Epidemiology \& Community Health. 2006 Nov $1 ; 60(11)$.

3. Lantz A, Holmer H, Finlayson SRG, Ricketts TC, Watters DA, Gruen RL, et al. Measuring the migration of surgical specialists. Surgery. 2020 Sep;168(3).

4. Gajewski J, Wallace M, Pittalis C, Mwapasa G, Borgstein E, Bijlmakers L, et al. Why Do They Leave? Challenges to Retention of Surgical Clinical Officers in District Hospitals in Malawi. International Journal of Health Policy and Management. 2020 Aug 5;

5. Hagander LE, Hughes CD, Nash K, Ganjawalla K, Linden A, Martins Y, et al. Surgeon Migration Between Developing Countries and the United States: Train, Retain, and Gain from Brain Drain. World Journal of Surgery. 2013 Jan 4;37(1).

6. Saluja S, Rudolfson N, Massenburg BB, Meara JG, Shrime MG. The impact of physician migration on mortality in low and middleincome countries: an economic modelling study. BMJ Global Health [Internet]. 2020 Jan 1 [cited 2021 Aug 20];5(1):e001535. Available from: https://gh.bmj.com/content/5/1/e001535

7. Gosselin RA, Gyamfi Y-A, Contini S. Challenges of Meeting Surgical Needs in the Developing World. World Journal of Surgery 2010 35:2 [Internet]. 2010 Nov 23 [cited 2021 Aug 20];35(2):258-61. Available from: https://link.springer.com/article/10.1007/s00268-010$0863-\mathrm{z}$

8. Telemedicine I of M (US) C on ECA of, Field MJ. Evolution and Current Applications of Telemedicine. 1996 [cited 2021 Aug 20]; Available from: https://www.ncbi.nlm.nih.gov/books/NBK45445/

9. Hoffer-Hawlik MA, Moran AE, Burka D, Kaur P, Cai J, Frieden TR, et al. Leveraging Telemedicine for Chronic Disease Management in Low- and Middle-Income Countries During Covid-19. Global Heart [Internet]. 2020 [cited 2021 Aug 20];15(1):63. Available from: /pmc/articles/PMC7500231/ 
10. Sayani S, Muzammil M, Saleh K, Muqeet A, Zaidi F, Shaikh T. Addressing cost and time barriers in chronic disease management through telemedicine: an exploratory research in select low- and middle-income countries: https://doi.org/101177/2040622319891587 [Internet]. 2019 Dec 4 [cited 2021 Aug 20];10. Available from: https://journals.sagepub.com/doi/10.1177/2040622319891587

11. Asiri A, AlBishi S, AlMadani W, ElMetwally A, Househ M. The Use of Telemedicine in Surgical Care: a Systematic Review. Acta informatica medica: AIM : journal of the Society for Medical Informatics of Bosnia \& Herzegovina : casopis Drustva za medicinsku informatiku $\mathrm{BiH}$ [Internet]. 2018 Oct;26(3):201-6. Available from: https://pubmed.ncbi.nlm.nih.gov/30515013

12. Cheriff AD, Schulam PG, Docimo SG, Moore RG, Kavoussi LR. Telesurgical consultation. Journal of Urology [Internet]. 1996;156(4):1391-3. Available from: https://www.scopus.com/inward/record.uri?eid=2-s2.0-0029845916\&doi=10.1016\%2fS0022$5347 \% 2801 \% 2965596-4 \&$ partnerID=40\&md5=574300b76e06c2fb8ee964b9953f5f 22

13. Raison N, Khan MS, Challacombe B. Telemedicine in Surgery: What are the Opportunities and Hurdles to Realising the Potential? Current Urology Reports [Internet]. 2015;16(7):43. Available from: https://doi.org/10.1007/s11934-015-0522-x

14. (SAGES) S of AGES. Guidelines for the surgical practice of telemedicine. Surgical Endoscopy [Internet]. 2000;14(10):975. Available from: https://doi.org/10.1007/s004640000290

15. Huang EY, Knight S, Guetter CR, Davis CH, Moller M, Slama E, et al. Telemedicine and telementoring in the surgical specialties: A narrative review. The American Journal of Surgery [Internet]. 2019;218(4):760-6. Available from: https://www.sciencedirect.com/science/article/pii/S0002961019301291

16. El-Sabawi B, Magee 3rd W. The evolution of surgical telementoring: current applications and future directions. Annals of translational medicine [Internet]. 2016 Oct;4(20):391. Available from: https://pubmed.ncbi.nlm.nih.gov/27867943

17. Valente DS, Silveira Eifler L, Carvalho LA, Filho GAP, Ribeiro VW, Padoin AV. Telemedicine and Plastic Surgery: A Pilot Study. Pu LLQ, editor. Plastic Surgery International [Internet]. 2015;2015:187505. Available from: https://doi.org/10.1155/2015/187505

18. Mendez I, Hill R, Clarke D, Kolyvas G, Walling S. Robotic Long-distance Telementoring in Neurosurgery. Neurosurgery [Internet]. 2005 Mar 1;56(3):434-40. Available from: https://doi.org/10.1227/01.NEU.0000153928.51881.27

19. Eadie LH, Seifalian AM, David son BR. Telemedicine in surgery. British Journal of Surgery [Internet]. 2003 Jun 1;90(6):647-58. Available from: https://doi.org/10.1002/bjs.4168 
20. World Bank Country and Lending Groups - World Bank Data Help Desk [Internet]. [cited 2021 Aug 20]. Available from: https://datahelpdesk.world bank.org/knowled gebase/articles/906519-world-bank-country-and-lending-groups

21. Nadjafi-Semnani M., Simforoosh N., Nahid Ghanbarzadeh N., Miri MR. Real-time point-to-point wireless intranet connection: first implication for surgical demonstration and telementoring in urologic laparoscopic surgery in Khorasan. Urology Journal. 2008;5(2):748.

22. A F, V K, SY G, E K, R P. Safe introduction of laparoscopic colorectal surgery even in remote areas of the world: the value of a comprehensive telementoring training program. Journal of laparoendoscopic \& advanced surgical techniques Part A [Internet]. 2015 [cited 2021 Aug 20];25(1):37-42. Available from: https://pubmed.ncbi.nlm.nih.gov/25469662/

23. Davis MC, Can DD, Pindrik J, Rocque BG, Johnston JM. Virtual Interactive Presence in Global Surgical Education: International Collaboration Through Augmented Reality. World Neurosurgery. 2016 Feb 1;86:103-11.

24. Rosser JC, Bell RL, Harnett B, Rodas E, Murayama M, Merrell R. Use of mobile low-bandwith telemedical techniques for extreme telemedicine applications. Journal of the American College of Surgeons. 1999 Oct 1;189(4):397-404.

25. Bauer JJ, Lee BR, Bishoff JT, Janetschek G, Bunyaratavej P, Kamolpronwijit W, et al. International Surgical Telementoring Using a Robotic Arm: Our Experience. https://home.liebertpub.com/tmj [Internet]. 2004 Jul 9 [cited 2021 Aug 20];6(1):25-31. Available from: https://www.liebertpub.com/doi/abs/10.1089/107830200311824

26. Jr. NRN, Mitre AI, Lima SVC, Fugita OE, Lima ML, Stoianovici D, et al. Telementoring Between Brazil and the United States: Initial Experience. https://home.liebertpub.com/end [Internet]. 2004 Jul 6 [cited 2021 Aug 20];17(4):217-20. Available from: https://www.liebertpub.com/doi/abs/10.1089/089277903765444339

27. PV P, SK M, S V, CG N, K R, R B. Telementoring in end ocrine surgery: preliminary Indian experience. Telemedicine journal and ehealth: the official journal of the American Telemedicine Association [Internet]. 2006 Feb [cited 2021 Aug 20];12(1):73-7. Available from: https://pubmed.ncbi.nlm.nih.gov/16478416/

28. Tamariz F, Merrell R, Popescu I, Onisor D, Flerov Y, Boanca C, et al. Design and Implementation of a Web-Based System for Intraoperative Consultation. World Journal of Surgery 2008 33:3 [Internet]. 2009 Jan 3 [cited 2021 Aug 20];33(3):448-54. Available from: https://link.springer.com/article/10.1007/s00268-008-9858-4 
29. Datta N, Macqueen IT, Schroeder AD, Wilson JJ, Espinoza JC, Wagner JP, et al. Wearable Technology for Global Surgical Teleproctoring. Journal of Surgical Education. 2015 Nov 1;72(6):1290-5.

30. Greenfield MJ, Luck J, Billingsley ML, Heyes R, Smith OJ, Mosahebi A, et al. Demonstration of the effectiveness of augmented reality telesurgery in complex hand reconstruction in Gaza. Plastic and Reconstructive Surgery - Global Open [Internet]. 2018 [cited 2021 Aug 20];6(3). Available from:

https://journals.lww.com/prsgo/Fulltext/2018/03000/Demonstration_of_the_Effectiveness_of_Augmented.26.aspx

31. McCullough MC, Kulber L, Sammons P, Santos P, Kulber DA. Google glass for remote surgical tele-proctoring in low- And middleincome countries: A feasibility study from Mozambique. Plastic and Reconstructive Surgery - Global Open [Internet]. 2018 [cited 2021 Aug 20];6(12). Available from:

https://journals.lww.com/prsgo/Fulltext/2018/12000/Google_Glass_for_Remote_Surgical_Tele_proctoring.20.aspx

32. Geary A, Benavent S, Cruz EAD la, Wayman L. Distance Surgical Mentorship for Ophthalmologists in Northern Peru. MedEdPublish [Internet]. 2019 Mar 11 [cited 2021 Aug 20];8(1). Available from: https://doi.org/10.15694/mep.2019.000045.1

33. Ologunde R, Maruthappu M, Shanmugarajah K, Shalhoub J. Surgical care in low and middle-income countries: Burden and barriers. International Journal of Surgery. 2014 Aug 1;12(8):858-63.

34. Friedrich MJ. Worldwide Disparities in Surgical Care. JAMA [Internet]. 2015 Jun 16 [cited 2021 Aug 20];313(23):2311-2311. Available from: https://jamanetwork.com/journals/jama/fullarticle/2320327

35. Ngwa W, Olver I, Schmeler KM. The Use of Health-Related Technology to Reduce the Gap Between Developed and Undeveloped Regions Around the Globe. https://doi.org/101200/EDBK_288613. 2020 Mar 31;(40):227-36.

36. Challacombe B, Wheatstone S. Telementoring and Telerobotics in Urological Surgery. Current Urology Reports 2010 11:1 [Internet]. 2010 Jan 5 [cited 2021 Aug 20];11(1):22-8. Available from: https://link.springer.com/article/10.1007/s11934-009-0086-8

37. Shimizu S, Nakashima N, Okamura K, Han H-S, Tanaka M. Telesurgery System with Original-Quality Moving Images over HighSpeed Internet: Expansion Within the Asia-Pacific Region. https://home.liebertpub.com/lap [Internet]. 2007 Oct 2 [cited 2021 Aug 20];17(5):673-8. Available from: https://www.liebertpub.com/doi/abs/10.1089/lap.2007.0017

38. Surgical Specialties — Royal College of Surgeons [Internet]. [cited 2021 Aug 20]. Available from: https://www.rcseng.ac.uk/careers-insurgery/trainees/foundation-and-core-trainees/copy-of-surgical-specialties/ 
39. Glass - Glass [Internet]. [cited 2021 Aug 20]. Available from: https://www.google.com/glass/start/

40. Ebrahim S, Pearce N, Smeeth L, Casas JP, Jaffar S, Piot P. Tackling Non-Communicable Diseases In Low-and Middle-Income Countries: Is the Evidence from High-Income Countries All We Need? PLOS Medicine [Internet]. 2013 Jan [cited 2021 Aug 20];10(1):e1001377. Available from: https://journals.plos.org/plosmedicine/article?id=10.1371/journal.pmed.1001377

41. Bawah A, Houle B, Alam N, Razzaque A, Streatfield PK, Debpuur C, et al. The Evolving Demographic and Health Transition in Four Low- and Middle-Income Countries: Evidence from Four Sites in the INDEPTH Network of Longitudinal Health and Demographic Surveillance Systems. PLOS ONE [Internet]. 2016 Jun 1 [cited 2021 Aug 20];11(6):e0157281. Available from: https://journals.plos.org/plosone/article?id=10.1371/journal.pone.0157281

42. Mendoza W, Miranda JJ. Global shifts in cardiovascular disease, the epidemiologic transition and other contributing factors: Towards a new practice of Global Health Cardiology. Cardiology clinics [Internet]. 2017 Feb 1 [cited 2021 Aug 20];35(1):1. Available from: /pmc/articles/PMC5134924/

43. Staton C, Vissoci J, Gong E, Toomey N, Wafula R, Abdelgadir J, et al. Road Traffic Injury Prevention Initiatives: A Systematic Review and Metasummary of Effectiveness in Low and Middle Income Countries. PLOS ONE [Internet]. 2016 Jan 6 [cited 2021 Aug 20];11(1):e0144971. Available from: https://journals.plos.org/plosone/article?id=10.1371/journal.pone.0144971

44. Tackling the global burden of road traffic injuries - Institute of Global Health Innovation [Internet]. [cited 2021 Aug 20]. Available from: https://blogs.imperial.ac.uk/ighi/2020/08/03/tackling-the-global-burden-of-road-traffic-injuries/

45. Vervoort D, Swain JBD, Pezzella AT, Kpodonu J. Cardiac Surgery in Low- and Middle-Income Countries: A State-of-the-Art Review. The Annals of Thoracic Surgery. 2021 Apr 1;111(4):1394-400.

46. PROXIMIE. Home - Proximie - Saving lives by sharing the world's best clinical practice [Internet]. [cited 2021 Aug 20]. Available from:

https://proximie.com/?gclid=Cj0KCQjwpf2IBhDkARIsAGVo0D3ru4_KwAI1Geca7fYTMeIozU8cRjJpk0BdT3oYruBlxLs16GbLmXE aAgsyEALw_wcB\#

47. Sackier JM, Wang Y. Robotically assisted laparoscopic surgery. Surgical Endoscopy 1994 8:1 [Internet]. 1994 Jan [cited 2021 Aug 20];8(1):63-6. Available from: https://link.springer.com/article/10.1007/BF02909496 
48. El-Sabawi B, Magee W, III. The evolution of surgical telementoring: current applications and future directions. Annals of Translational Medicine [Internet]. 2016 Oct 1 [cited 2021 Aug 20];4(20). Available from:/pmc/articles/PMC5107399/

49. Amato M, Eissa A, Puliatti S, Secchi C, Ferraguti F, Minelli M, et al. Feasibility of a telementoring approach as a practical training for transurethral enucleation of the benign prostatic hyperplasia using bipolar energy: a pilot study. World Journal of Urology 2021

[Internet]. 2021 Feb 4 [cited 2021 Aug 20];1-7. Available from: https://link.springer.com/article/10.1007/s00345-021-03594-9

50. Google Glass Enterprise Edition 2 announced for \$999 [Internet]. [cited 2021 Aug 20]. Available from: https://www.cnbc.com/2019/05/20/google-glass-enterprise-edition-2-announced-price.html

51. Providers - Glass [Internet]. [cited 2021 Aug 20]. Available from: https://www.google.com/glass/providers/

52. McKnight RR, Pean CA, Buck JS, Hwang JS, Hsu JR, Pierrie SN. Virtual Reality and Augmented Reality-Translating Surgical Training into Surgical Technique. Current Reviews in Musculoskeletal Medicine [Internet]. 2020 Dec 1 [cited 2021 Aug 20];13(6):663. Available from: /pmc/articles/PMC7661680/

53. Madder R. Robot surgery could be the future of remote health care |Fortune. Fortune [Internet]. 2020 Feb 11 [cited 2021 Aug 20]; Available from: https://fortune.com/2020/02/11/tele-robotics-surgery-5g-health/

54. Song F, Hooper L, Loke YK. Publication bias: what is it? How do we measure it? How do we avoid it? Open Access Journal of Clinical Trials [Internet]. $2013 \mathrm{Jul} 4$ [cited 2021 Aug 20];5(1):71-81. Available from: https://www.dovepress.com/publication-bias-what-is-ithow-do-we-measure-it-how-do-we-avoid-it-peer-reviewed-fulltext-article-OAJCT

55. Zemmar A, Lozano AM, Nelson BJ. The rise of robots in surgical environments during COVID-19. Nature Machine Intelligence 2020 2:10 [Internet]. 2020 Oct 13 [cited 2021 Aug 20];2(10):566-72. Available from: https://www.nature.com/articles/s42256-020-00238-2

56. S M, D P, N S. Sustainable Development Goals (SDGs), and their implementation: A national global framework for health, development and equity needs a systems approach at every level. British medical bulletin [Internet]. 2017 Dec 1 [cited 2021 Aug 20];124(1):81-90. Available from: https://pubmed.ncbi.nlm.nih.gov/29069332/ 
Figure legends:

Figure 1: PRISMA Flow chart 


\section{Figure 1}
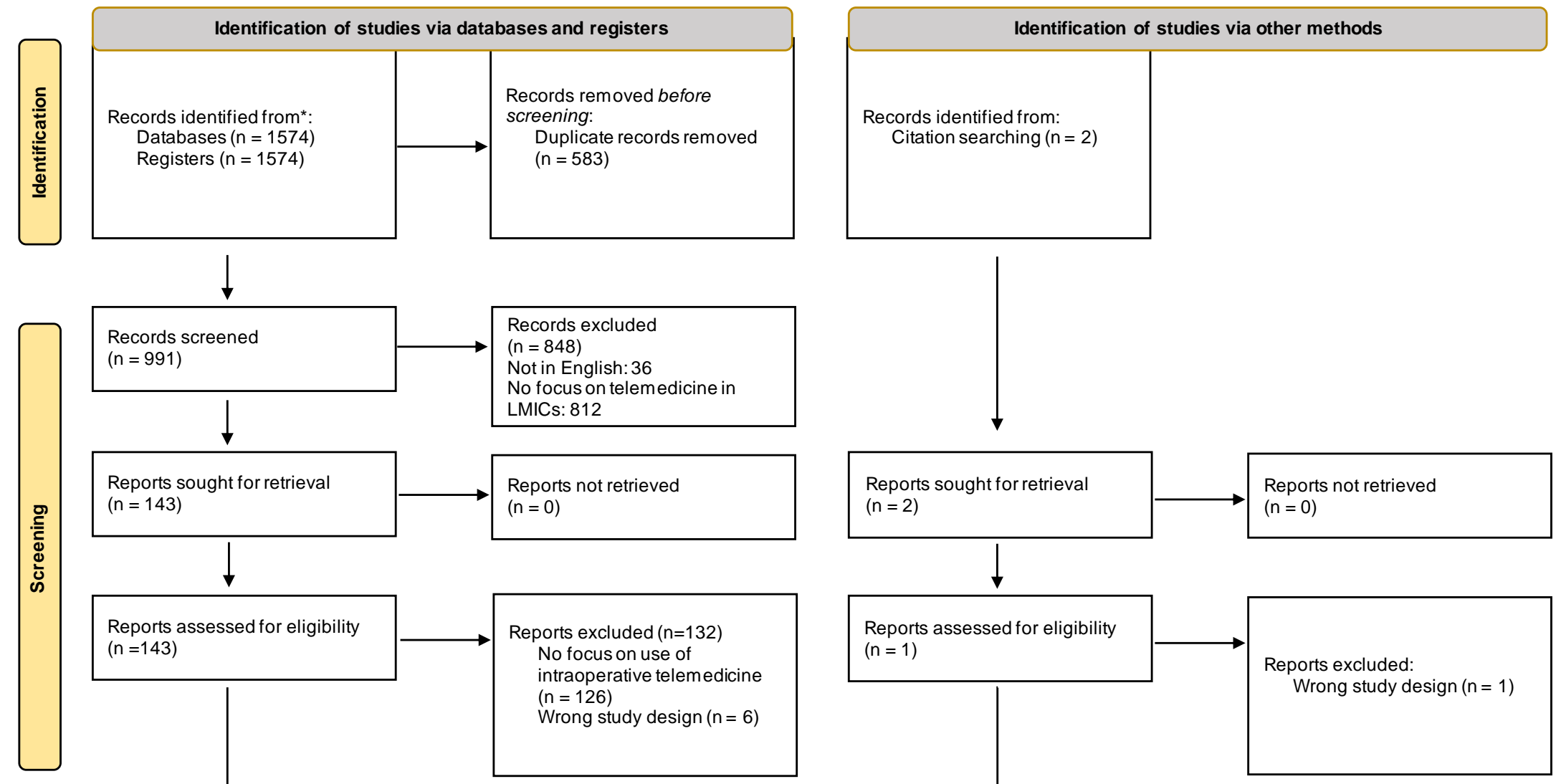

Studies included in review

$(n=12)$

Reports of included studie

$(n=12)$

Records screened

$(\mathrm{n}=991)$

$\downarrow$

Reports sought for retrieval

$(n=143)$

Reports assessed for eligibility $(n=143)$

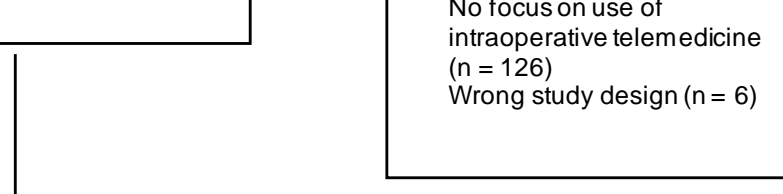

intraoperative telemedicine

Wrong study design $(n=6)$

\section{Records excluded}

$(\mathrm{n}=848)$

Not in English: 36

emedicine in

LMICs: 812

Reports not retrieved

$(n=0)$ 
